\title{
Numerical simulation of one-dimensional aluminum particle-air detonation with realistic heat capacities
}

\author{
Honghui Teng* , Zonglin Jiang \\ State Key Lab of High Temperature Gas Dynamics, Institute of Mechanics, Chinese Academy of Sciences, Beijing 100190, China
}

\section{A R T I C L E I N F O}

\section{Article history:}

Received 18 January 2012

Received in revised form 18 June 2012

Accepted 22 October 2012

Available online 1 December 2012

\section{Keywords:}

Al particle

Detonation wave

Heat capacity

Hybrid model

\begin{abstract}
A B S T R A C T
Aluminum (Al) particle-air detonation is very complicated because it includes multi-phase combustion phenomenon. Thus numerical simulations are often over-simplified. Here, the detonation is simulated by solving one-dimensional equations with more realistic heat capacities that vary with the dust mixture temperature. The effect on detonation parameters from the realistic heat capacities for the solid particles is investigated with a hybrid combustion model. The calculated results indicate that the detonation pressure, temperature and velocity vary significantly with changes in the heat capacity. Except for the velocity, these parameters are overestimated in numerical simulations when a constant heat capacity of the pre-shock mixtures is used. Furthermore, the realistic heat capacities have a strong effect on small diameter particles, but a weak effect on large diameter particles. Thus, when constant heat capacities are used, the combustion characteristic lengths are a function of the particle diameters with a power dependence of 1.77 , whereas the power dependence decreases to 1.49 when realistic heat capacities are used. Moreover, if realistic heat capacities are applied, an "abnormal" strong detonation wave may appear in a dust mixture having large diameter particles. This phenomenon is consistent with the current combustion model, but it indicates that the value of heat released should also vary with the gas temperature in a fashion similar to that of the heat capacities.
\end{abstract}

(c) 2012 The Combustion Institute. Published by Elsevier Inc. All rights reserved.

\section{Introduction}

Aluminum $(\mathrm{Al})$ particle detonations that release chemical reaction heat from Al fast combustion have many engineering applications [1] such as solid rocket propellants [2,3] and, more recently, potential applications in hypersonic propulsion. The Al-air mixture detonation propagates in the same manner as gaseous detonations: its post-shockwave combustion will produce intensive heat release, and then sustain a strong leading shock. However, the Al particle is usually thought to vaporize first, which make the combustion diffusion-controlled [4]. This feature is similar to liquid fuel detonations, whereas gaseous fuel detonation is controlled by kinetics. Al-air detonation has some unique characteristics when compared to liquid fuel detonation. First, the $\mathrm{Al}$ particles are usually covered by an aluminum oxide $\left(\mathrm{Al}_{2} \mathrm{O}_{3}\right)$ shell that affects detonation ignition. The second characteristic is that the combustion will generate solid $\mathrm{Al}_{2} \mathrm{O}_{3}$, which may further influence detonation product expansion. These multi-phase interactions make $\mathrm{Al}$ combustion very complicated, resulting in many unresolved problems [5,6].

For heterogeneous post-shock combustion, the chemical reaction time and length scales are much longer than those for homogeneous combustion. It is very difficult to carry out dusty

\footnotetext{
* Corresponding author.

E-mail address: hhteng@imech.ac.cn (H. Teng).
}

detonation experiments, so there are only a few Al-air detonation experiments that have been reported. Tulis and Selman [7] studied Al dusty detonations for flake and spherical particles, and demonstrated that the specific area is a very sensitive parameter. Borisov et al. [8] examined the role of particle dimensions and noted that the parameters velocity and the pressure depend on the minimum particle scale. Zhang et al. [9] investigated transverse waves in dusty detonations and calculated, using a detonation model, the minimum tube diameter for generating detonation. Moreover, the flame acceleration [10] and deflagration to detonation transition [11] in the $\mathrm{Al}$ suspended mixtures are also studied experimentally. Based on experimental results, theoretical and numerical models were developed to study Al dust detonation. A general two-phase mixture model was proposed by Baer and Nunziato [12] to study the deflagration-to-detonation transition in granular explosives. Papalexandris $[13,14]$ developed a two-phase model by applying the classical theory of irreversible processes and the generalized concept of a low-Mach-number approximation. Federov et al. $[15,16]$ applied a non-equilibrium model of steady Al-oxygen detonations to calculate parameters for one- and two-dimensional cellular detonations. Recently, numerical simulation has become a very useful tool in dusty detonation research. Papalexadris $[17,18]$ examined the structure and stability of detonations in mixtures of gases and solid particles that could be either combustible or inert. Benkiewicz and Hayashi $[19,20]$ simulated one-dimensional and 


\begin{tabular}{|c|c|c|c|}
\hline \multicolumn{4}{|c|}{ Nomenclature } \\
\hline$C$ & mole concentration, $\mathrm{mol} / \mathrm{m}^{3}$ & $t$ & time, $s$ \\
\hline$C_{d}$ & drag coefficient & $T$ & gas temperature, $\mathrm{K}$ \\
\hline$d p$ & particle diameter, $\mathrm{m}$ & $u$ & gas velocity, $\mathrm{m} / \mathrm{s}$ \\
\hline E & activation energy, $\mathrm{J} / \mathrm{mol}$ & $u_{p}$ & particle velocity, $\mathrm{m} / \mathrm{s}$ \\
\hline$e_{p}$ & particle internal energy, $\mathrm{J} / \mathrm{mol}$ & $W_{i}$ & molecular weight, g/mol \\
\hline$K$ & diffusion reaction coefficient, $\mathrm{s} / \mathrm{m}^{2}$ & $\mu$ & dynamic viscosity coefficient, $\mathrm{kg} /(\mathrm{m} \mathrm{s})$ \\
\hline$k_{d}$ & rate coefficient of diffusion reaction, $\mathrm{kg} \mathrm{m} /(\mathrm{mol} \mathrm{s})$ & $v_{i}$ & stoichiometric coefficient \\
\hline$K_{s}$ & rate coefficient of kinetic reaction, $\mathrm{kg} \mathrm{m} /(\mathrm{mol} \mathrm{s})$ & $\rho$ & gas density, $\mathrm{kg} / \mathrm{m}^{3}$ \\
\hline$K_{0}$ & kinetic reaction coefficient, & & \\
\hline$L_{b}$ & Al boiling latent heat, $\mathrm{J} / \mathrm{mol}$ & \multicolumn{2}{|c|}{ Subscripts } \\
\hline$L_{m}$ & Al melting latent heat, $\mathrm{J} / \mathrm{mol}$ & $g$ & gas-phase index \\
\hline $\operatorname{Re}_{s}$ & two-phase Reynolds number & & \\
\hline
\end{tabular}

two-dimensional cellular structures of Al-oxygen detonation and discussed the influence of particle diameter. Federov et al. $[21,22]$ calculated both ideal and cellular detonation diffraction, and compared the results with gaseous detonation to reveal the special characteristics of dusty detonation. Veyssiere et al. [23] studied $\mathrm{Al}$-air and $\mathrm{Al}$-oxygen detonation initiations and found that the critical initiation energy is correlated with the cellular width. They also found that both the induction length and the cellular widths have an exponential relationship with particle diameters, which provides a very useful quantitative result.

Despite research progress on $\mathrm{Al}$-air detonations, not enough is known to develop a reliable combustion model. Up to now, the diffusion-controlled model [24] has been the standard choice in the combustion simulation. However, a study on Al combustion by Lynch et al. [25] demonstrated that the combustion of particles with diameters less than $10 \mu \mathrm{m}$ would be dependent on pressure and mole fraction. If the particle diameter is of nanometer scale, the combustion becomes kinetics-controlled rather than diffusion-controlled [26,27]. Tanguay et al. [28] found that the even the particle with the diameter $100 \mu \mathrm{m}$, the kinetics-controlled combustion may appear due to the high-speed flow behind the leading shock of the detonation. Usually, the diameter of Al particles is less than $5 \mu \mathrm{m}$, thus kinetics-controlled combustion is relevant. However, a detailed model has not yet been developed for fine particles [29]. Zhang et al. [30] proposed a hybrid model for their detonation simulations based on a combination of diffusion-controlled and kinetics-controlled combustions. Briand et al. [31] used this model for cellular detonation simulations, and also compared their results with those from the classic diffusion model. The particle heat capacities in the hybrid model are constant, following the setting in the diffusion models [17-23]. Because the particle realistic heat capacities vary with temperature in a wide range, this setting should be replaced when kinetics-controlled combustion is included. Therefore, realistic heat capacities are used here in a hybrid combustion simulation model for Al particle detonation, and the effects of using the realistic heat capacities relative to using constant values are examined.

\section{Physical and mathematical model}

\subsection{Governing equations}

The governing equations of the gas mixtures can be written as: $\frac{\partial U_{g}}{\partial t}+\frac{\partial E_{g}}{\partial x}=S_{g}+H_{g}$

where $S_{g}$ is the source term induced by the chemical reaction and $H_{g}$ is the source term induced by the gas-particle interaction. The multi-fluid method is used to model the solid particle, and the governing equations can be written as:

$\frac{\partial U_{p}}{\partial t}+\frac{\partial E_{p}}{\partial x}=S_{p}+H_{p}$

The detailed term expressions can be found out in Ref. [30]. The Eqs. (1) and (2) are solved separately, and the interaction of the gas and particles are achieved through the source terms.

To complete the equations, the source terms needs to be modeled. The phase interaction force can be written as:

$f_{x}=C_{d} \sum_{i=1}^{m} n_{i} \frac{\pi d_{p i}^{2}}{4} \rho\left(u-u_{p}\right) \sqrt{\left(u-u_{p}\right)^{2}} / 2$

where the drag coefficient is

$C_{d}=\frac{24}{\operatorname{Re}_{s}}\left(1+\frac{1}{6} \operatorname{Re}_{s}^{2 / 3}\right)$

And the heat conduction is

$Q_{d}=\sum_{i=1}^{m} n_{i} \pi d_{p i} N u \lambda\left(T-T_{p}\right)$

$N u=2.0+0.459 \operatorname{Re}_{s}^{0.55} \operatorname{Pr}^{0.33}$

$\operatorname{Re}_{s}=\frac{\rho \sqrt{\left(u-u_{p}\right)^{2}}}{\mu} \sum_{i=1}^{m} d_{p i}$

\subsection{Combustion model}

The combustion model is the most important part in the detonation simulation. Zhang et al. [30] proposed the hybrid model considering both the diffusion and the kinetic combustion. In this model the $\mathrm{Al}$ combustion rate is

$J_{1}=-n_{1} \pi d_{p 1}^{2} k_{1}=-n_{1} \pi d_{p 1}^{2} \frac{v_{1} W_{1}}{v_{o x i} W_{o x i}} k$ 
$k=\frac{k_{d} k_{s}}{k_{d}+k_{s}} C_{o x i}$

Combing Eqs. (8) and (9), the total reaction rate can be calculated. For the diffusion combustion [32], the reaction rate $K_{d}$ is

$k_{d}=\frac{v_{o x i} W_{o x i}}{v_{1} W_{1}} \frac{\rho_{p 1} d_{p 1}}{2 C_{\text {total }} K d_{p 1,0}^{2}}\left(1+0.276 \operatorname{Re}_{s}^{1 / 2} \operatorname{Pr}^{1 / 3}\right)$

For the kinetic combustion, the reaction rate $K_{s}$ is

$k_{s}=k_{0} e^{-E / R T_{s}}$

In this paper, the constants used in the chemical model are the same as those in the previous paper [30], which are $K=4 \times 10^{6} \mathrm{~s}$ / $\mathrm{m}^{2}, K_{0}=1.2 \times 10^{3} \mathrm{~kg} \mathrm{~m} /(\mathrm{mol} \mathrm{s}), E=71.7 \mathrm{KJ} / \mathrm{mol}$. The reaction rates with various particle diameters in the case of the temperature $933 \mathrm{~K}$ and $2792 \mathrm{~K}$ are shown in Fig. 1. Generally the diffusion reaction rate varies with particle diameters, but does not vary with the temperature. On the other hand the kinetic reaction rate varies with the temperature, but does not vary with particle diameters. When the temperature is the melting point of Al $933 \mathrm{~K}$, the diffusion rate is much higher than the kinetic rate for the particle whose diameter on the several-micron scale. Then the rate of the hybrid model will mainly dependent on the kinetic rate, as shown in Fig. 1a. When the temperature is near the boiling point of $\mathrm{Al}$ about $2792 \mathrm{~K}$, the total reaction rate will decided by the diffusion reaction as shown in Fig. $1 \mathrm{~b}$.

Figure 1 explains why the diffusion model is acceptable in the detonation simulation before. In the Al-air detonation, the postshock temperature rises quickly and most of the Al particles combust in the diffusion-controlled environment. One disadvantage is the artificial ignition temperature is needed to decide when the combustion will start. However the hybrid reaction model introduced the kinetic reaction so that the combustion can be calculated in the whole flow field uniformly. In the low temperature region, the combustion is also available but controlled by the very slow kinetic rate. In this model, the ignition temperature, which introduces some uncertainties in the diffusion model, is abandoned. This is helpful to improve the simulation accuracy.

\subsection{Realistic heat capacity method}

Although this hybrid model makes progress in the Al-air detonation, there needs some improvements. In the classic diffusion

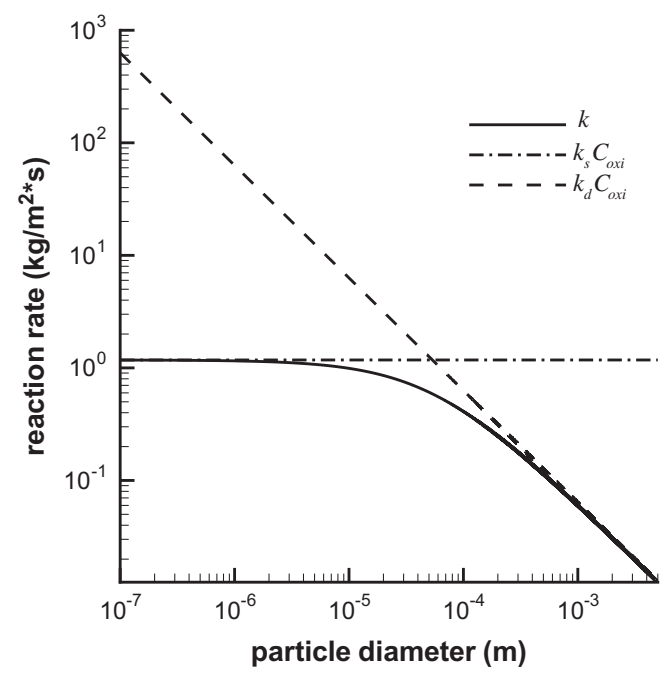

(a) model, the combustion layer following the shock wave closely cannot be simulated correctly, because the temperature in that region is not high enough and the combustion is suppressed by the ignition temperature. The hybrid model improves the combustion model so the combustion is on in this region. However, this region is closely adjacent to the shock wave and the temperature covers a rather wide range. Therefore both the gas and solid specie properties change in a wide range. In the gaseous detonation research, the detailed chemical reaction model has been used with the realistic gas specie properties widely [33,34]. In the Al detonation research before, the simplified model is used and the heat capacity of the solid particle is set to be a constant. This is acceptable for the diffusion model, but should be improved when the hybrid model is used. The heat capacities of $\mathrm{Al}$ and $\mathrm{Al}$ oxide changing with the temperature [35] are shown in Fig. 2. When the temperature is $300 \mathrm{~K}$, the heat capacity of $\mathrm{Al}$ is about $24.2 \mathrm{~J} / \mathrm{mol} \mathrm{K}$, and it changes to be $32.3 \mathrm{~J} / \mathrm{mol} \cdot \mathrm{K}$ given the temperature $900 \mathrm{~K}$. A discontinuity on the curve exists near the melting temperature $933 \mathrm{~K}$, which derives from the phase change. For the $\mathrm{Al}$ oxide, the heat capacity is about $79.3 \mathrm{~J} / \mathrm{mol} \mathrm{K}$ given the temperature $300 \mathrm{~K}$, and increases to be $138.8 \mathrm{~J} / \mathrm{mol} \mathrm{K}$ given the temperature $2300 \mathrm{~K}$. For the melting liquid Al oxide whose temperature is above $2327 \mathrm{~K}$, the heat capacity jumps to be $192.5 \mathrm{~J} / \mathrm{mol} \mathrm{K}$. Because the heat capacity changes along with the temperature in a wide range, this effect will influence the results intensely and should be considered in the hybrid model.

The heat capacity of the solid particle is associated with the particle internal energy and the particle temperature, which are important in the energy equation and the source terms. For a fixed heat capacity, the temperature can be written as

$$
T_{p}= \begin{cases}e_{p} / c_{p} & e_{p} \leq c_{p} T_{p, m} \\ T_{p, m} & c_{p} T_{p, m}<e_{p} \leq c_{p} T_{p, m}+L_{m} \\ \left(e_{p}-L_{m}\right) / c_{p} & \text { for } \quad c_{p} T_{p, m}+L_{m}<e_{p} \leq c_{p} T_{p, b}+L_{m} \\ T_{p, b} & c_{p} T_{p, b}+L_{m}<e_{p} \leq c_{p} T_{p, b}+L_{m}+L_{b} \\ \left(e_{p}-L_{m}-L_{b}\right) / c_{p} & e_{p}>c_{p} T_{p, b}+L_{m}+L_{b}\end{cases}
$$

where $T_{p, m}$ is the melting temperature and $T_{p, b}$ is the evaporation temperature. However the realistic heat capacity is not a constant, but changes a lot with the temperature. In Eq. (12), the heat capacity should be replaced by the average heat capacity $\bar{c}\left(T_{p}\right)$, which can be written as

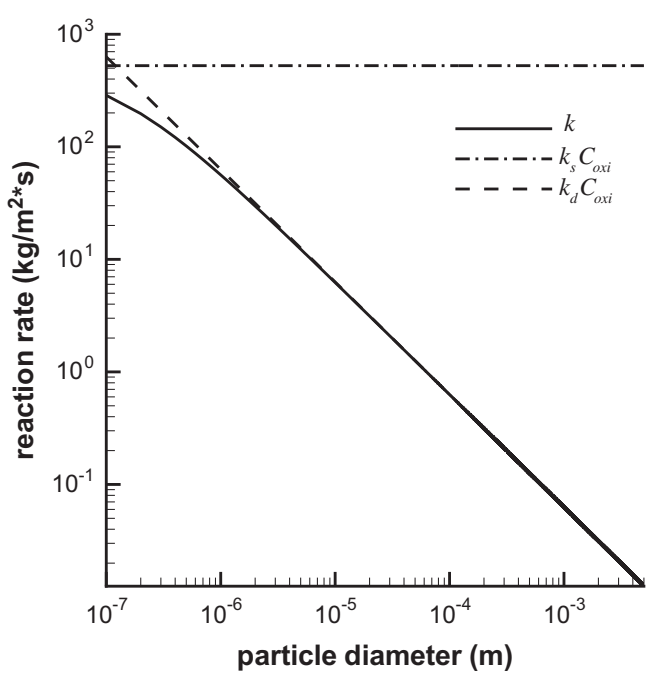

(b)

Fig. 1. The chemical reaction rates with different particle diameters (a) temperature $933 \mathrm{~K}$ and (b) temperature $2792 \mathrm{~K}$. 


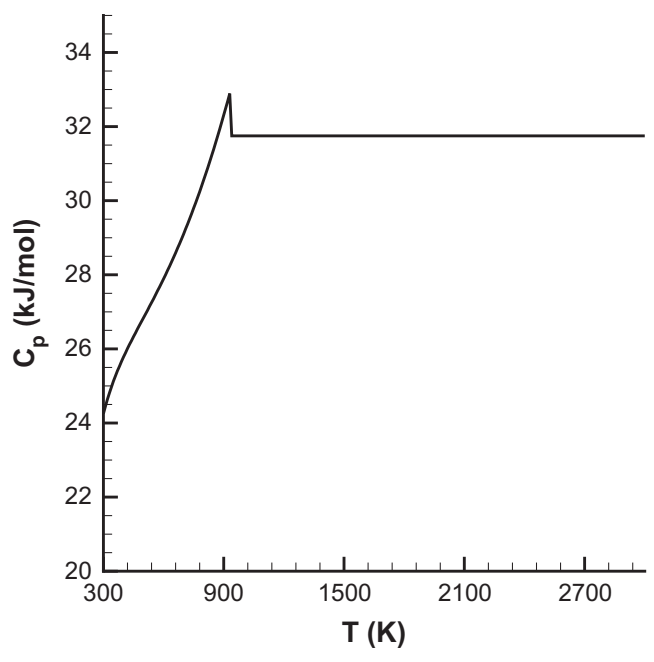

(a)

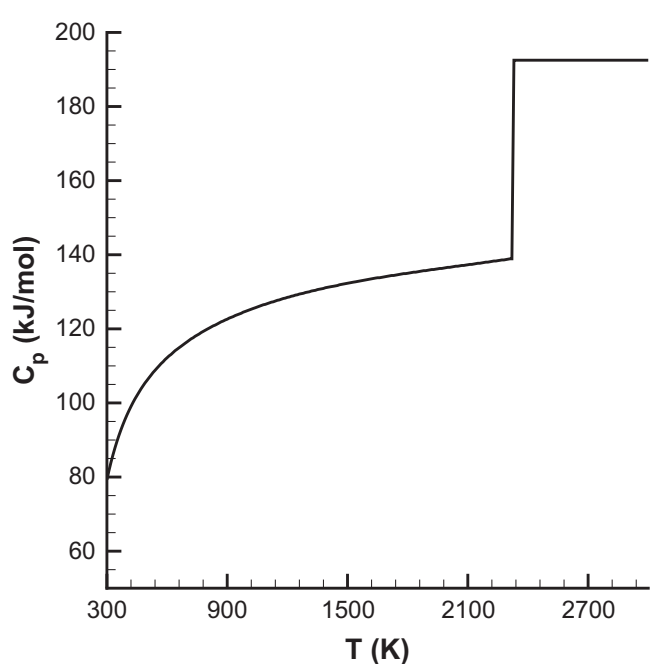

(b)

Fig. 2. The heat capacity of $\mathrm{Al}$ (a) and $\mathrm{Al}$ oxide (b) as the function of the temperature.

$\bar{c}_{p}=\frac{\int_{T_{0}}^{T_{p}} c_{p}(T) d T}{T_{p}-T_{0}}$

where $T_{0}$ is the temperature before the detonation wave.

In the simulation, there are two processes dealing with the particle temperature $T_{0}$ and internal energy $e_{p}$. The first one is calculate internal energy from the temperature. Combing Eqs. (12) and (13), it is similar to the process with the fixed heat capacities. However, calculating the temperature from the internal energy is more complicated. Because the relation between the temperature and internal energy is not linear, Eq. (12) cannot be used directly. For the convenience of the calculation, the average heat capacity $\bar{c}\left(T_{p}\right)$ is first integrated for a wide range of the given temperature. Usually the iterative process is needed to get the temperature, which is used to get the gaseous temperature in this paper. However this process is of low efficiency, and the another method is used to get the particle temperature. First the internal energy list is calculated as function of the given temperature and particle fraction. When the internal energy is given, the temperature calculation is simplified into the searching process in the internal energy list. The searching process has higher efficiency than the iterative process and the accuracy is not influenced. Numerical tests proved the accuracy can be guaranteed if the energy list step is small enough, which is chosen as $5 \mathrm{~K}$.

In this paper, two gas species $\mathrm{O}_{2}(\mathrm{~g})$ and $\mathrm{N}_{2}(\mathrm{~g})$ are simulated with the mole concentration $1: 4$ and two kinds of solid particles $\mathrm{Al}(\mathrm{s})$ and $\mathrm{Al}_{2} \mathrm{O}_{3}(\mathrm{~s})$ are simulated. In some research, the $\mathrm{Al}(\mathrm{g})$ vapor is included above the $\mathrm{Al}$ boiling temperature and the $\mathrm{Al}_{2} \mathrm{O}_{3}$ may be treated as the gas specie $\mathrm{Al}_{2} \mathrm{O}_{3}(\mathrm{~g})$. Because there are some uncertainties on the multi-phase processes, they are not included except the gas-particle force and heat conduction shown in Eqs. (3) and (5). This research focuses on the influence of the realistic heat capacity of the solid particles, and the phase change process is simply modeled through the latent heat shown in Eq. (12). The latent heats of $\mathrm{Al}_{2} \mathrm{O}_{3}(\mathrm{~s})$ are relatively small, only the latent heats of $\mathrm{Al}(\mathrm{s})$ are considered. The melting latent heat $L_{m}$ is $10.7 \mathrm{~kJ} / \mathrm{mol}$, while the boiling latent heat $L_{b}$ is $290 \mathrm{~kJ} / \mathrm{mol}$. The heat release of Al combustion is given as $838 \mathrm{~kJ} / \mathrm{mol}$, and Pr is fixed to be 0.72 . The chemical reaction is simplified to be

$4 \mathrm{Al}(\mathrm{s})+3 \mathrm{O}_{2}(\mathrm{~g}) \rightarrow 2 \mathrm{Al}_{2} \mathrm{O}_{3}(\mathrm{~s})$

In the simulation, the properties of the gas changes with the temperature [36], but the chemical reaction and the dissociation are not considered. The shock-capturing method is DispersionControlled Dissipation scheme [37], which is one kind of the TVD serial schemes. Following Zhang's experiment [38,39], the initial pressure is $2.5 \mathrm{~atm}$ and the temperature is $300 \mathrm{~K}$. The Al-particle average densities are $1250 \mathrm{~g} / \mathrm{m}^{3}$ and there is no $\mathrm{Al}_{2} \mathrm{O}_{3}(\mathrm{~s})$ initially.

\section{Numerical results and discussion}

\subsection{Detonation waves with fixed heat capacities}

To examine the effects of heat capacity, the Al-air detonation is first simulated with constant heat capacities. The pressure profiles in Fig. 3 are shown as a function of time, where the constant heat capacities are set to the values at $300 \mathrm{~K}$. The grid scale is $0.0005 \mathrm{~m}$ and the calculation domain is $6.0 \mathrm{~m}$ in length. The detonation is initiated by a small zone having a high temperature and pressure near the left side of the domain. The self-sustained detonation is formed and a constant speed is gradually reached. The Al-air detonation induces a self-similar expansion wave as seen in gaseous detonations; however, as shown in Fig. 4, there are different features near the leading shock wave. There are two pressure peaks

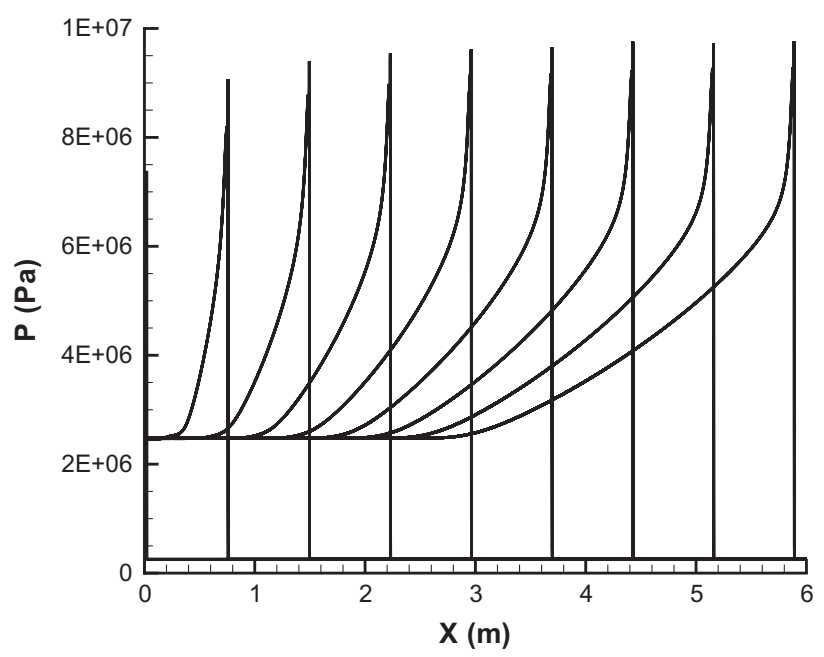

Fig. 3. Pressure profiles of $\mathrm{Al}$-air detonation calculated with constant heat capacities. 


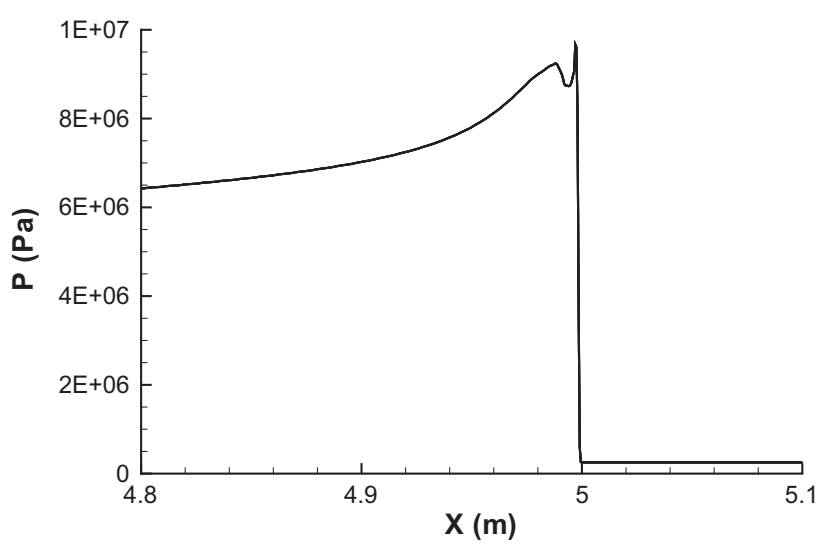

(a)

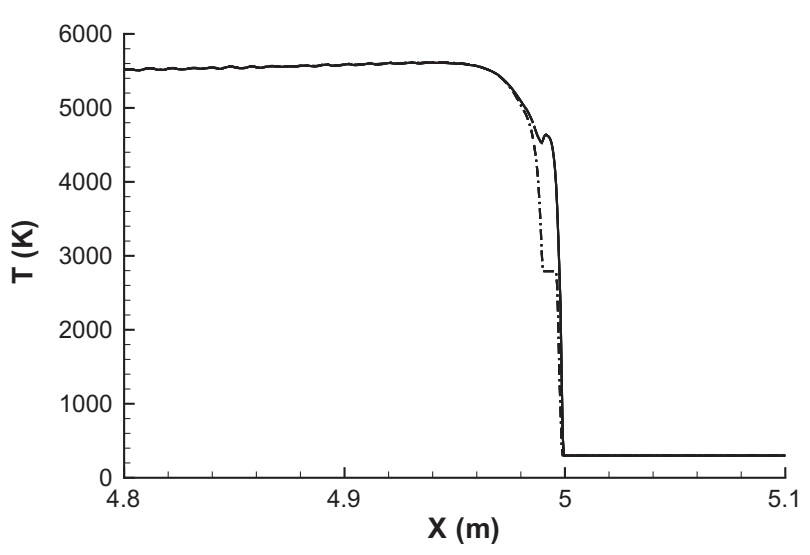

(b)

Fig. 4. Profiles of the pressure (a) and temperature (b) of Al-air detonation calculated with constant heat capacities (solid line for gas; dash-dot line for particles).

in Fig. 4a. The first one is the leading shock, which compresses and ignites the gas-particle mixture. The other is due to particle relaxation from a mechanism that will be discussed later. The temperature profiles in Fig. $4 \mathrm{~b}$ highlight the differences between the gas and particle mixtures. For the particles, the latent heat induces a plateau in the temperature profile, which corresponds to the boiling point. The melting latent heat is only about $5 \%$ of the boiling latent heat, so that plateau is not significant. The post-shock gas temperature is high and heat is transferred from the gas phase to particles. Once the boiling latent heat is exhausted, the particle temperature rises quickly, and the two temperature curves start to overlap.

From numerical results, the pressure peak reaches 38.4 times that of the initial pressure, and the product temperature is over $5500 \mathrm{~K}$. In previous simulations [30], the peak pressure is 37.6 times that of the initial pressure and the product temperature is $5000 \mathrm{~K}$. The detonation velocity is $1828 \mathrm{~m} / \mathrm{s}$ in the present simulation, and $1758 \mathrm{~m} / \mathrm{s}$ in the previous simulations. These differences occur because the $\mathrm{Al}$ evaporation process and the induced $\mathrm{Al}(\mathrm{g})$ are not included in the present simulation. As note earlier, metal combustion is very complicated and there are several multi-phase interaction processes, so it is almost impossible to include them in the current model. These processes slow the combustion and reduce the detonation velocity. To get a reasonable temperature, the endothermic reaction that produces $\mathrm{AlO}(\mathrm{g})$ was introduced to control the temperature [20]. In this simulation, the multi-phase processes that include $\mathrm{Al}$ evaporation and $\mathrm{AlO}(\mathrm{g})$ production are not considered, so it is possible to clearly demonstrate the effects of heat capacity.

To ascertain the grid effect, the detonation pressure profiles calculated with different grid resolutions (mesh sizes) are shown in Fig. 5. When the mesh size is $0.004 \mathrm{~m}$, the numerical result shows only one pressure peak at 36.8 , and it appears similar to gaseous detonations. When the mesh size is $0.002 \mathrm{~m}$, another pressure peak appears and its value is higher than the first one, as shown in Fig. 5a. Refining the grid further, the first pressure peak increases while the second pressure peak decreases, as shown in Fig. 5b. The wave front structure is similar to the one simulated by Zhang et al. [30] with a mesh size of $0.001 \mathrm{~m}$. The results for mesh sizes of $0.0005 \mathrm{~m}$ and $0.0002 \mathrm{~m}$, respectively, are shown in Fig. $5 \mathrm{c}$ and $\mathrm{d}$. The two pressure peaks appear the same, and have similar values. When $\mathrm{Al}$-air detonations propagate, there is a small oscillation on the first pressure peak, depicted in Fig. 3. Therefore, the first peak pressure cannot be exactly the same when detonations reach the same position. We chose the second pressure peak as the criterion for checking for grid convergence because it monotonically approaches a constant value. In Fig. 5, the second peak values are $37.56,37.24,37.04$, and 37.01 , which correspond to mesh sizes of $0.002 \mathrm{~m}, 0.001 \mathrm{~m}, 0.0005 \mathrm{~m}$, and $0.0002 \mathrm{~m}$, respectively. In the following simulations, the mesh size of $0.0005 \mathrm{~m}$ is used as the default grid.

\subsection{The role of realistic heat capacities}

Numerical results simulated with realistic heat capacities are shown in Fig. 6, and the flow field near the leading shockwave is shown in Fig. 7. The detonation wave clearly differs from those in Fig. 3 and 4 that had constant heat capacities. Because the heat capacity varies with temperature, the post-shock average heat capacity becomes larger and larger. This leads to decreases in both pressure and temperature. In this case, the first peak pressure is 32.2 times higher than the initial pressure while the second peak pressure is 25.8 times. Meanwhile the product temperature decreases to $4600 \mathrm{~K}$, and the temperature relaxation length becomes much longer. Grid resolution tests were carried out to make sure the results are grid independent. With the mesh sizes of 0.0005 $\mathrm{m}$ and $0.0002 \mathrm{~m}$, the pressure profiles in Fig. 8 almost overlap. This demonstrates that the $0.0005 \mathrm{~m}$ mesh size is adequate for simulating the $\mathrm{Al}$-air detonation.

To ascertain the mechanism of the differences between constant and realistic heat capacities, the temperature and the mole fraction of Al particles are plotted in Fig. 9. The temperature rise is slower in the case of realistic heat capacities and its post-plateau region is much longer relative to those for the case of constant heat capacity. In the post-plateau region, the temperature will continue to increase for a constant heat capacity, but this temperature rise is not observable for the realistic heat capacities. Although the temperature is not physically accurate, it does indicate that realistic heat capacities affect the results significantly. Experimentally [40], the peak pressure is 26.0-28.4 times higher than the initial pressure and the velocity is about $1470 \mathrm{~m} / \mathrm{s}$. In the simulations with constant heat capacities, the pressure is 38.4 times higher than the initial pressure and the velocity is $1828 \mathrm{~m} / \mathrm{s}$. For the simulations with the realistic heat capacities, the pressure is 32.2 times higher than the initial pressure and the velocity is $1630 \mathrm{~m} / \mathrm{s}$. For the given parameters, the CJ detonation velocity is $1750 \mathrm{~m} / \mathrm{s}$, which is lower than that for the constant heat capacity and higher than that for the realistic heat capacities. The $\mathrm{CJ}$ detonation calculation is based on the assumption that the state behind the leading shockwave is at equilibrium, which introduces the deficit of the experimental velocity. Because only the gas-particle forces and heat conduction are considered, the detonation velocity should be lower than the CJ velocity, but higher than the experimental one. From this 


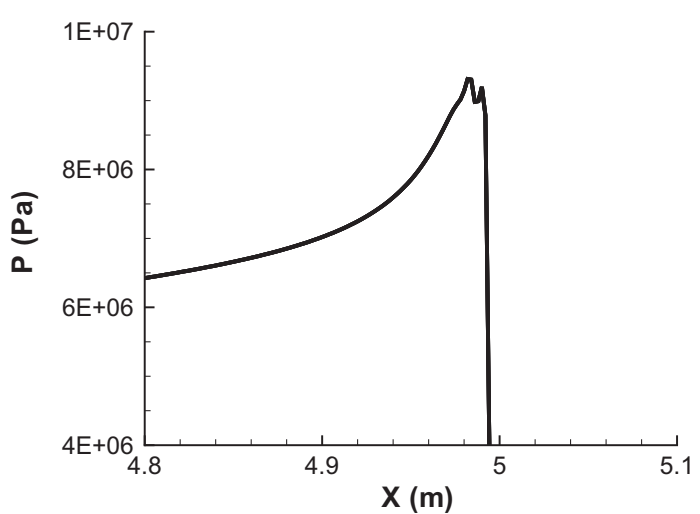

(a)

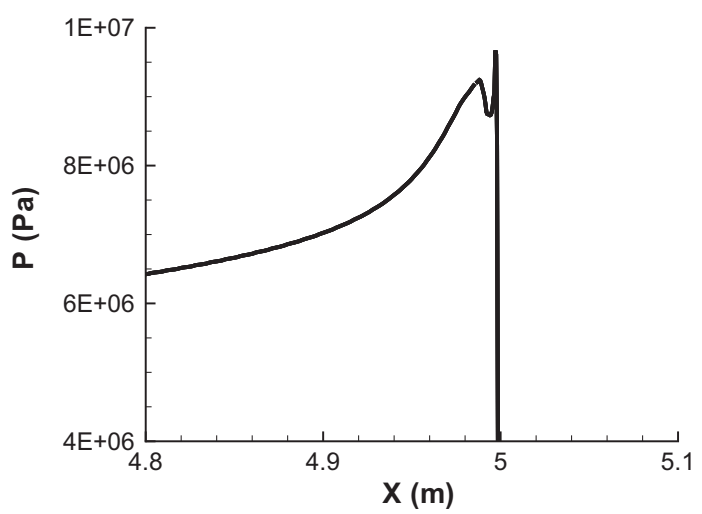

(c)

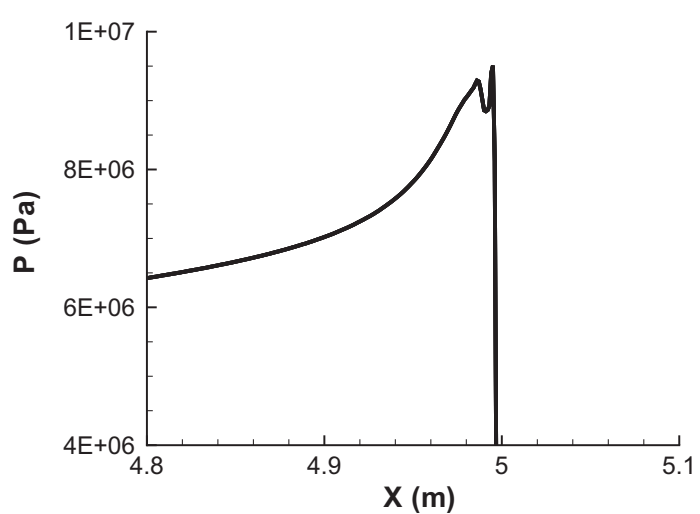

(b)

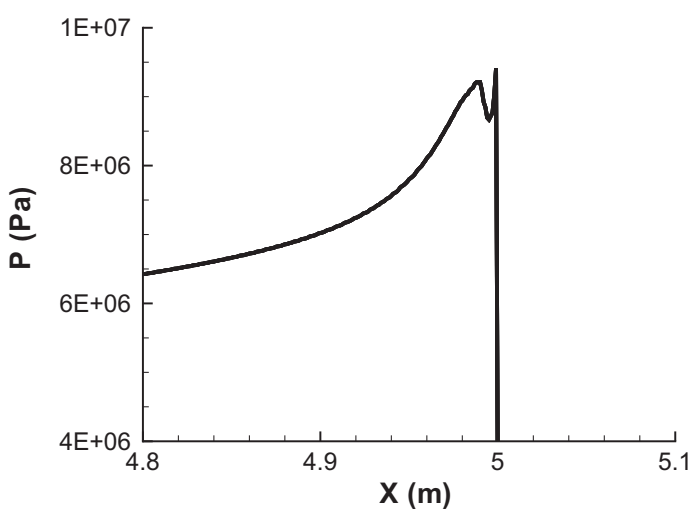

(d)

Fig. 5. Pressure profiles of $\mathrm{Al}$-air detonation based on different grid resolutions (mesh sizes): (a) $0.002 \mathrm{~m}$; (b) $0.001 \mathrm{~m}$; (c) $0.0005 \mathrm{~m}$ and (d) $0.0002 \mathrm{~m}$.

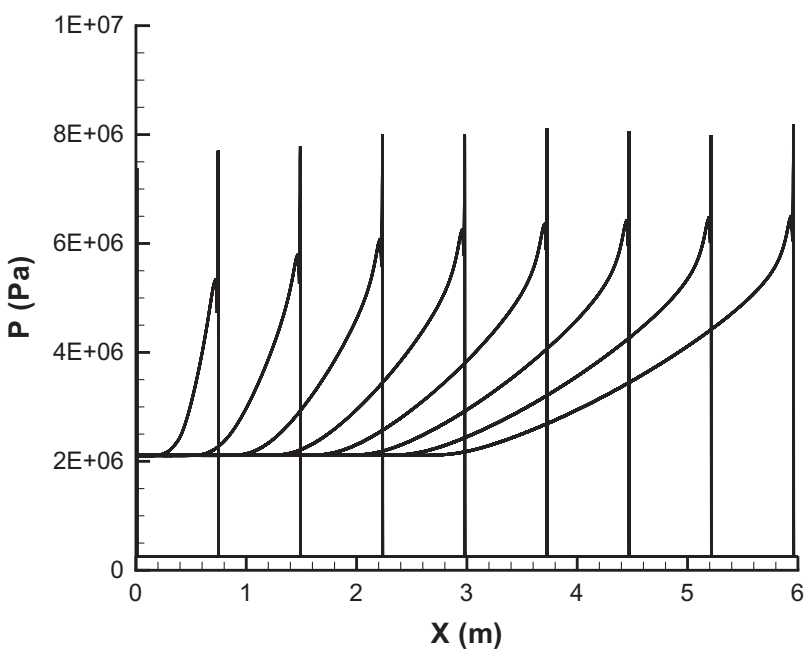

Fig. 6. Pressure profiles of Al-air detonation waves with realistic heat capacities.

viewpoint, the results with the realistic heat capacities are an improvement relative to those for the constant heat capacity, and thus should be better for Al-air detonation modeling.

In gaseous detonation simulations with a simplified combustion model [40], the heat capacity of the detonation product is commonly used to calculate the internal energy. Therefore the heat capacities fixed at the constants of liquid $\mathrm{Al}$ and $\mathrm{Al}_{2} \mathrm{O}_{3}$, are used to simulate the detonations, shown in Fig. 10. Theoretically speaking, only a narrow region adjacent to the shockwave should be influenced by the variable heat capacity, where the temperature is below the melting temperature of $\mathrm{Al}$ at $933 \mathrm{~K}$ or that of $\mathrm{Al}_{2} \mathrm{O}_{3}$ at $2327 \mathrm{~K}$. However, the numerical results in Fig. 10 show that the pressure and temperature profiles change significantly in the whole flow field. The peak pressure is 30.2 and the peak temperature is $3600 \mathrm{~K}$. These values are much smaller than those for the realistic heat capacity simulations. The velocity is $1610 \mathrm{~m} / \mathrm{s}$, close to $1630 \mathrm{~m} / \mathrm{s}$ for the realistic heat capacity case, but much smaller than the $1828 \mathrm{~m} / \mathrm{s}$ velocity for the constant heat capacity case. There is a plateau in the pressure and temperature profiles in Fig. 10, and the second pressure peak is 14.2 times higher than the initial pressure. Although these results are better than those shown in Figs. 3 and 4 with constant heat capacities, they are still not accurate enough to approach the realistic heat capacity results.

\subsection{The influence of particle diameters}

Two cases for a particle diameter of $6.0 \mu \mathrm{m}$ are carried out with a constant and a realistic heat capacity, respectively. The pressure profile with the constant heat capacities is shown in Fig. 11. Because the particle diameter increases, the detonation needs a long path to reach steady state. Theoretically, the detonation of a large particle diameter needs a long relaxation time, and large initiation energy may help to achieve steady detonation more quickly. So the ignition pressure and temperature remain the same, but the ignition zone length is set to $0.5 \mathrm{~m}$, which is 25 times longer than the previous cases. When the detonation propagates to the position at $x=10.0 \mathrm{~m}$, steady detonation is observable and relaxation is very slow after the leading shock. Nevertheless, the particle diameter does not influence the peak pressure and velocity. The 


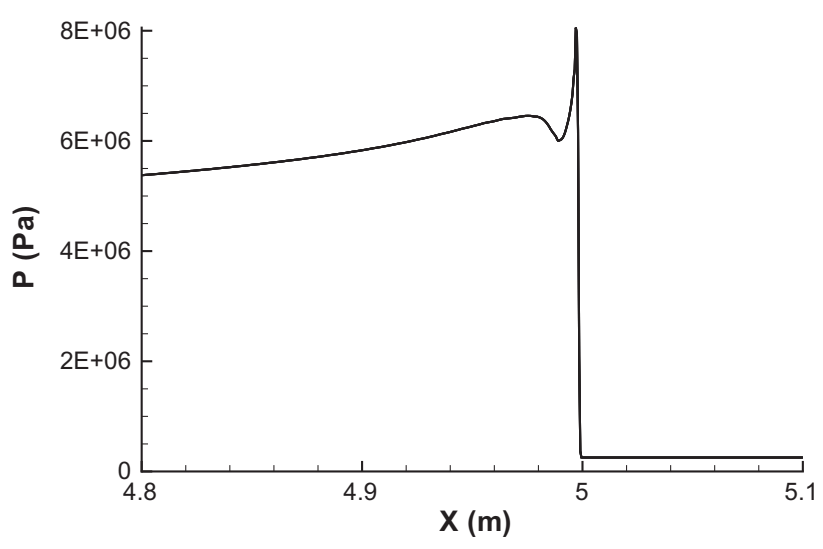

(a)

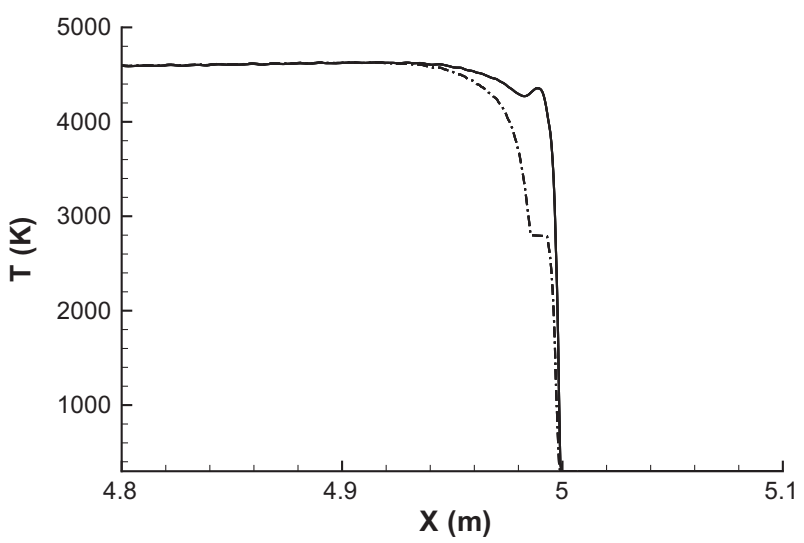

(b)

Fig. 7. Profiles of the pressure (a) and temperature (b) of Al-air detonation calculated with a realistic heat capacity (solid line for gas; dash-dot line for particle).

detonation velocity is $1822 \mathrm{~m} / \mathrm{s}$, which is close to the $1828 \mathrm{~m} / \mathrm{s}$ velocity for the $2.0 \mu \mathrm{m}$ diameter particle in the first case. The pressure and temperature profiles near the leading shock are shown in Fig. 12 at the position $x=10.0 \mathrm{~m}$. Both the pressure and temperature profiles are similar to those in the first case, but the corresponding length scales, such as the distance between the two pressure peaks and the length of the temperature plateau, are much larger. This is because the reaction should be slow for large diameter particles. Furthermore, a large particle diameter increases the force on a single particle, but the total force between the particles and the gas will become small. The small force and a slow reaction rate lead to the long relaxation process.

The pressure and temperature profiles near the leading shockwave calculated using realistic heat capacities are shown in Fig. 13. The peak pressure is 36.3 , which is higher than the 32.2 shown in Figs. 6 and 7 with the particle diameter $2.0 \mu \mathrm{m}$, and the second pressure peak is not visible. The temperature is $5260 \mathrm{~K}$ and higher than the $4600 \mathrm{~K}$ obtained in the second case. Furthermore, the detonation velocity is $1776 \mathrm{~m} / \mathrm{s}$, which is larger than the $1630 \mathrm{~m} / \mathrm{s}$ velocity in the $2.0 \mu \mathrm{m}$ diameter case, but very close to the $\mathrm{CJ}$ velocity of $1750 \mathrm{~m} / \mathrm{s}$. This is contrary to previous results $[20,23]$ in a qualitative sense, and has not been reported. The "abnormal" detonation seems to be unphysical because the large particle detonation is hard to initiate and the velocity should be slow.

In order to explain why big diameter particles can sustain a strong detonation, particle fractions of $\mathrm{Al}$ and $\mathrm{Al}_{2} \mathrm{O}_{3}$ are shown in

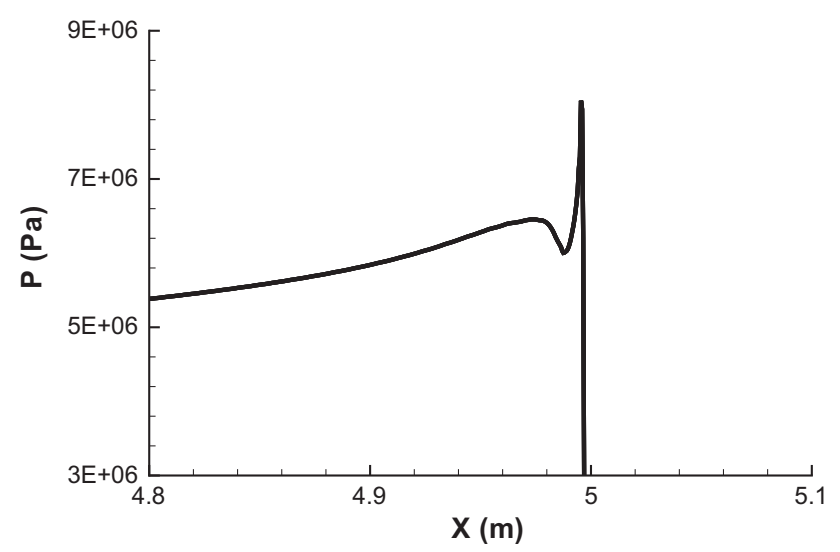

(a)

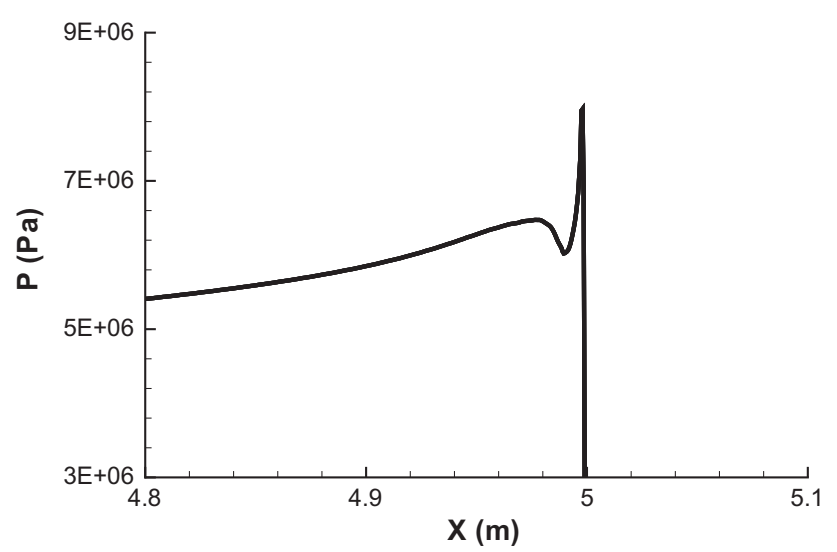

(b)

Fig. 8. Pressure profiles of $\mathrm{Al}$-air detonation with realistic heat capacities for two grids (mesh size): (a) $0.0005 \mathrm{~m}$ and (b) $0.0002 \mathrm{~m}$.

Fig. 14. First of all, the length scales of both the constant and realistic heat capacity cases increase as the particle diameter increases from $2.0 \mu \mathrm{m}$ to $6.0 \mu \mathrm{m}$. However, the changes are different. In the realistic heat capacity case, the temperature plateau increases slowly and there is a large portion of $\mathrm{Al}$ at the end. This part of Al will burn after the plateau and induce further temperature increases. This process happens in Figs. 8a, 14a and b, but is not observable in Fig. 8b. To ascertain the difference between two realistic heat capacity cases having different diameter particles, a quantitative study of the post-shockwave characteristic lengths are necessary. Generally there are three parts in the temperature profile, divided by the temperature plateau. The $\mathrm{Al}(\mathrm{s})$ percentage at the starting and end points of the temperature plateau are shown in Table 1. In the two cases having constant heat capacities, the starting point of the $6.0 \mu \mathrm{m}$ diameter case moves forward to $61.4 \%$, relative to that $60.5 \%$ of the $2.0 \mu \mathrm{m}$ diameter case. At the same time, the end point moves backward from $38.4 \%$ to $37.8 \%$. In the two cases of the realistic heat capacity, the starting point of the $6.0 \mu \mathrm{m}$ diameter case moves forward to $52.9 \%$, relative to that $50.9 \%$ of the $2.0 \mu \mathrm{m}$ diameter case, while the end point of the $6.0 \mu \mathrm{m}$ particle case moves forward from $36.8 \%$ to $43.9 \%$. Thus, the relative position of the plateau clearly moves forward with particle size. This change causes the post-plateau temperature rise, which in turn may be responsible for the "abnormal" detonation. This is reasonable within this combustion model, but it is not a physical detonation. The numerical results are thus not perfect, and more attention has to be paid to detonation modeling. 


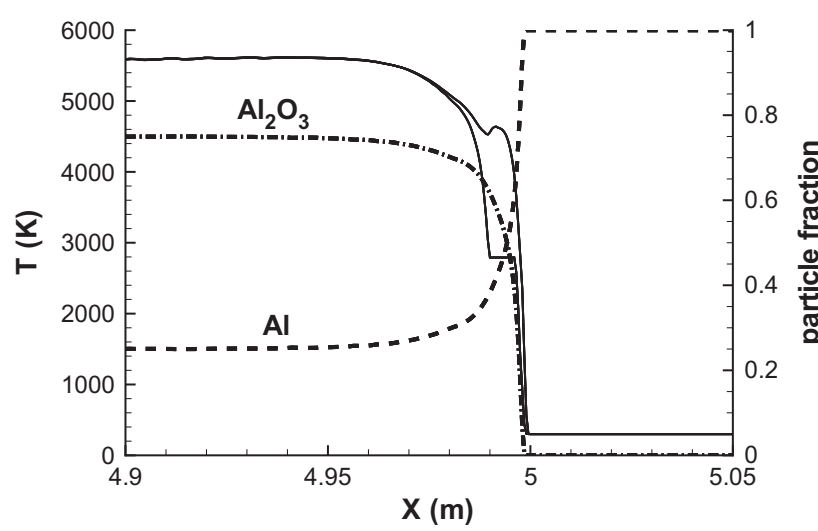

(a)

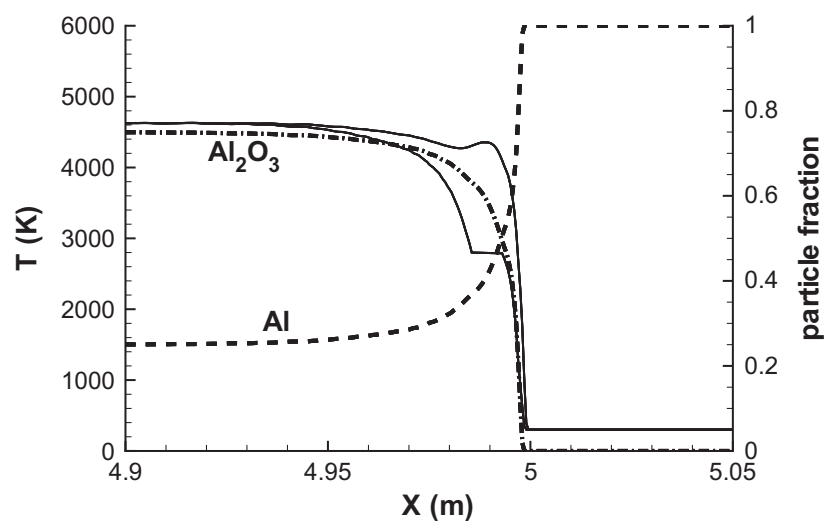

(b)

Fig. 9. Particle fraction (dashed) of Al-air detonation with a particle diameter of $2.0 \mu \mathrm{m}$ : (a) constant heat capacity and (b) realistic heat capacity.

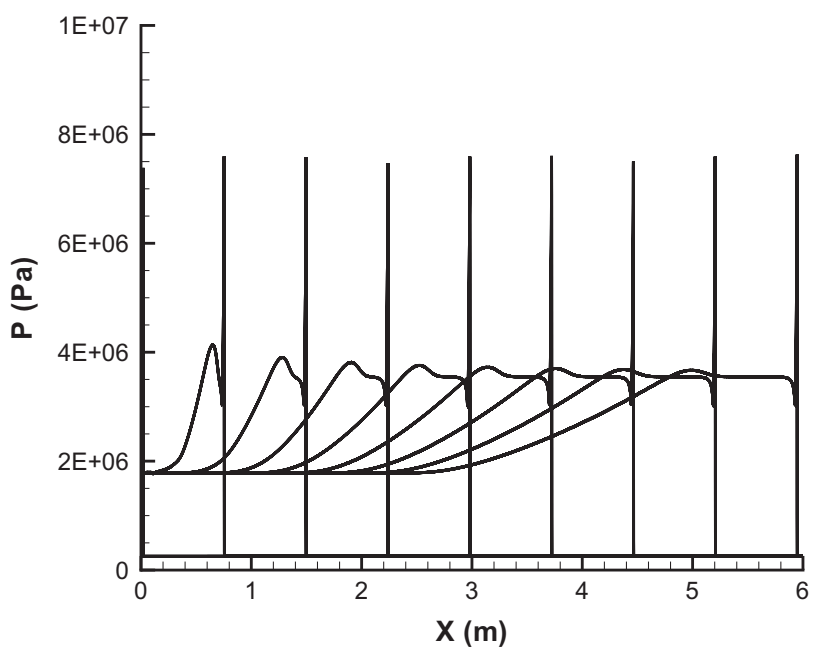

Fig. 10. Pressure profiles for $\mathrm{Al}$-air detonation calculated with a constant heat capacity from the liquid phase.

\subsection{Discussion: Al-air detonation characteristics}

The numerical results have showed that a realistic heat capacity has a significant influence on Al-air detonation parameters, and the effect is associated to the particle diameters. One of the detonation characteristics is the presence of two pressure peaks in

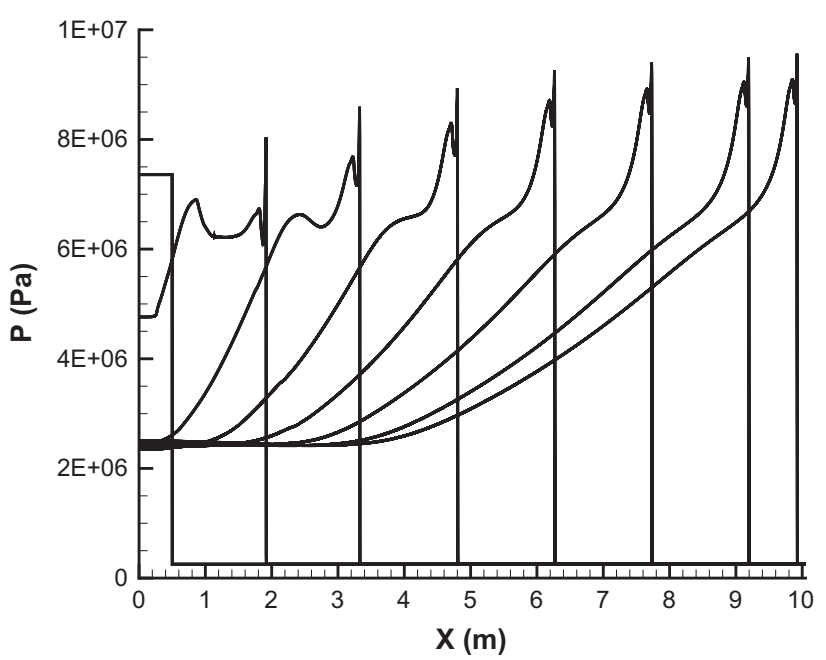

Fig. 11. Pressure profiles for Al-air detonation calculated with a constant heat capacity for a particle diameter of $6.0 \mu \mathrm{m}$.

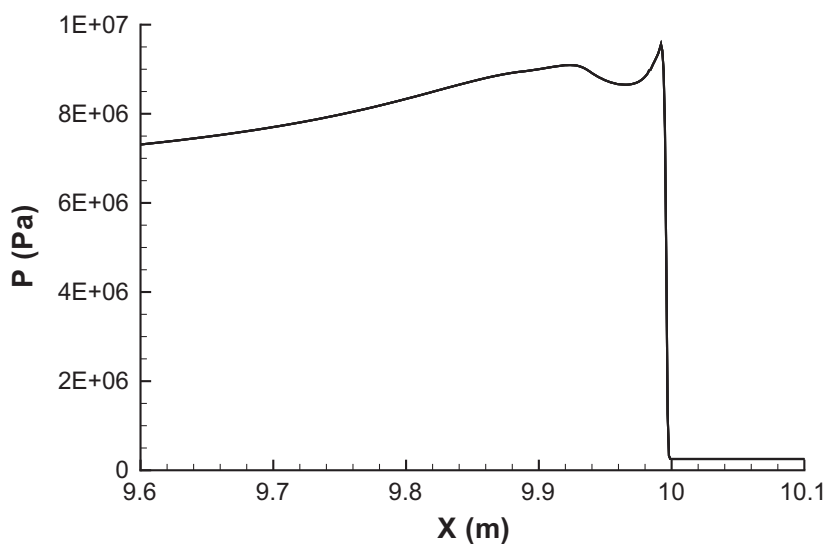

(a)

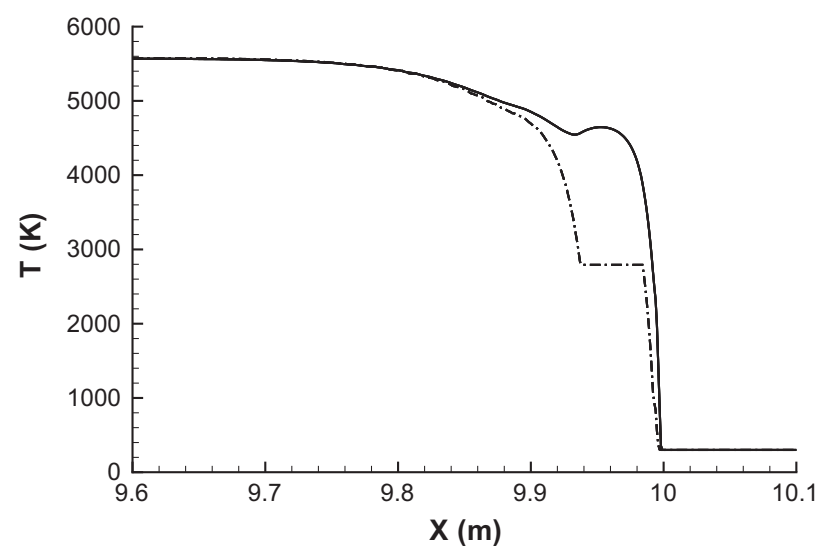

(b)

Fig. 12. Pressure and temperature profiles of $\mathrm{Al}$-air detonation calculated with constant heat capacities for a particle diameter of $6.0 \mu \mathrm{m}$ (solid line: gas; dash-dot line: particle): (a) pressure and (b) temperature.

the detonation profile; its development is helpful to understand the mechanism of the Al-air detonation. In the case of the constant heat capacities for the $2.0 \mu \mathrm{m}$ particle, the second pressure peak 


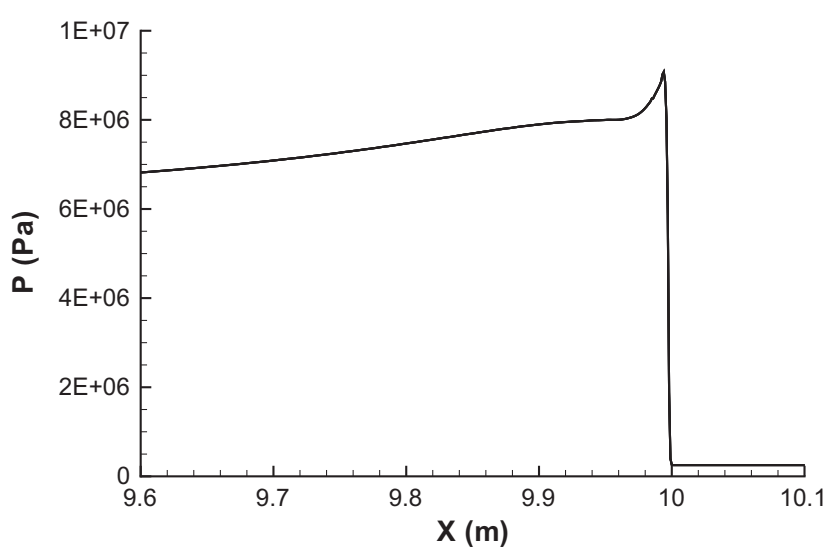

(a)

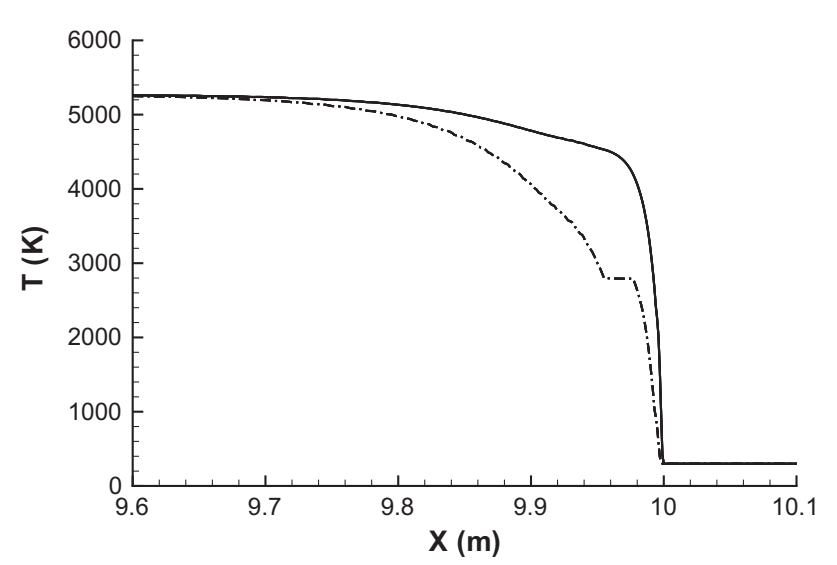

(b)

Fig. 13. Pressure and temperature profiles for Al-air detonation calculated with a realistic heat capacity for a particle diameter of $6.0 \mu \mathrm{m}$ (solid line: gas; dash-dot line: particle): (a) pressure; and (b) temperature.

value is close to the leading shockwave value, while in the case of the realistic heat capacities for the same particle, the second peak is much lower than the first one. Using a constant heat capacity from the liquid phase, the peak becomes obscure. Therefore, a higher heat capacity will lead to a lower second peak; this is also observed when the higher heat capacity is due to a larger particle diameter $(6.0 \mu \mathrm{m})$. This "double-front" detonation was studied widely and its origin is attributed to the delayed combustion of the Al particle [41]. However, it is possible to form the second peak in an inert gas containing dust particles, due to the high particle concentration accumulated behind the initial detonation front [42]. In this simulation, the $\mathrm{Al}$ combustion is tightly coupled with the leading shockwave and quickly produces solid $\mathrm{Al}_{2} \mathrm{O}_{3}$, as shown in Figs. 9 and 14. Because the realistic heat capacities and the large particle diameters will make the concentration rise slowly, the second peak becomes weak. Thus the conclusion that the high particle concentration induces the second peak is supported by the numerical results.

Although there are still some problems when using the realistic heat capacities, the combustion calculation before the plateau region is reliable and the quantitative investigation into the characteristic lengths has been accomplished. Before the plateau, the combustion is dominated by both diffusion-controlled and kinetics-controlled mechanisms, while the remaining part is influenced only by the diffusion-controlled mechanism. The length scale is a strong function of the particle diameter and the heat capacity. Veyssiere et al. [23,31] demonstrated that the induction length

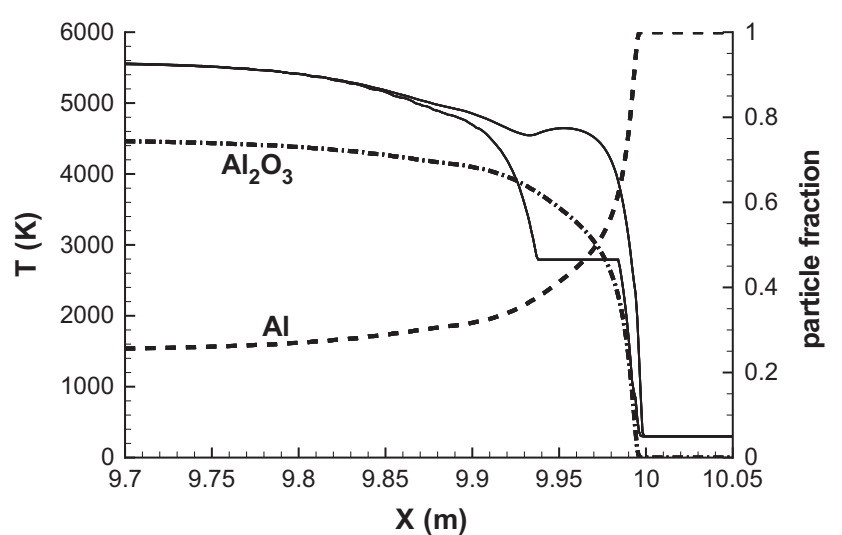

(a)

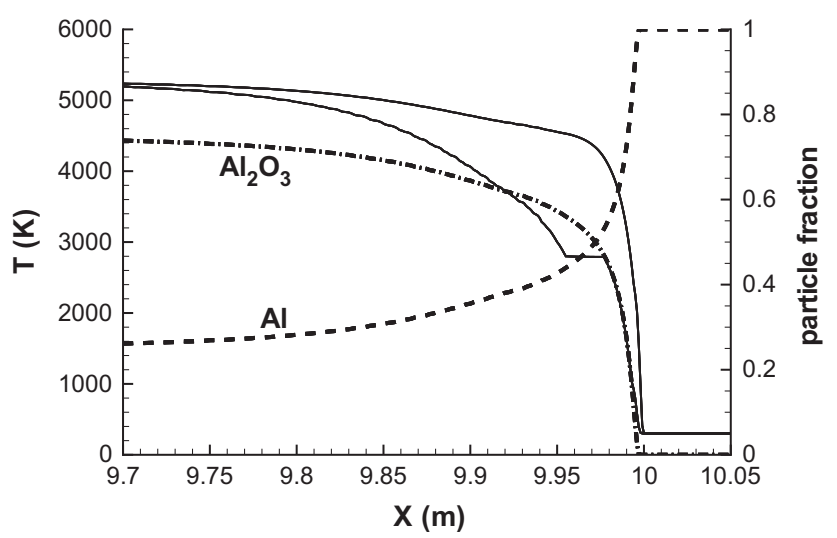

(b)

Fig. 14. Particle fractions of Al-air detonation calculated with the fixed (a) and realistic (b) heat capacities for a particle diameter of $6.0 \mu \mathrm{m}$.

Table 1

$\mathrm{Al}(\mathrm{s})$ percentage at the starting and end points of the temperature plateau.

\begin{tabular}{llllll}
\hline & \multicolumn{2}{l}{ Constant heat capacity } & & \multicolumn{2}{l}{ Realistic heat capacity } \\
\cline { 2 - 3 } \cline { 6 - 7 } \cline { 6 - 7 } & Start (\%) & End (\%) & & Start (\%) & End (\%) \\
\hline $2.0 \mu$ m Diameter & 60.5 & 38.4 & & 50.5 & 36.8 \\
$6.0 \mu$ m Diameter & 61.4 & 37.8 & & 52.9 & 43.9 \\
\hline
\end{tabular}

and the combustion length obey a power law dependence of the particle diameter. If the induction length is defined as the distance between the leading front and the point where the gradient of particle temperature becomes a maximum, the power law dependence is about 1.4. If the combustion length is defined from the moment when the relative decrease in the particle radius becomes noticeable $(>0.1 \%$ in Ref. [31]) to the point where this radius becomes smaller than $10 \%$ of the initial radius, the power law dependence is about 1.8. The combustion length definition is different when the latent heat induces the plateau. The length before the temperature plateau is a characteristic length of the combustion. As seen in Table 1, when the diameter increases by a factor of three, the starting point varies little in the frame of the chemical reaction process; so it can be chosen as the characteristic combustion length. The length variation as a function of particle diameter is shown in Fig 15. For the constant heat capacity cases, the power law dependence is about 1.77 , which is close to the previous value of 1.8[31]. Since it is a mixture of the induction length and the combustion length, this value is physical. However, the power 


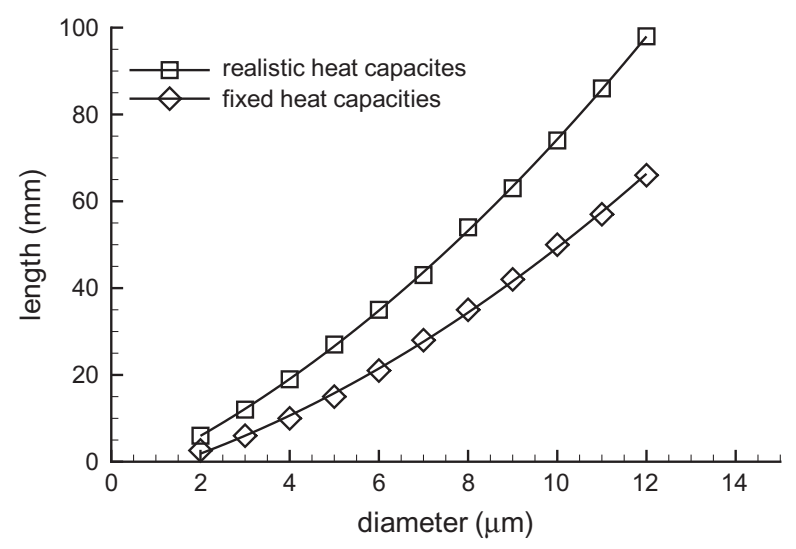

Fig. 15. Characteristic length of $\mathrm{Al}$-air detonation as a function of particle diameter.

law decreases to about 1.49 for the realistic heat capacity cases, which deviates far from 1.8. This is because the effect is strong for small particles and weak for the large particles, which is shown in Fig. 15. Thus, the heat capacity effects are dependent on the particle diameters.

\section{Conclusion}

Al-air detonation was simulated in order to study the effect of heat capacity on detonation parameters. The heat capacity is used for calculating the internal energy of a particle, but its variation with temperature has been previously ignored. The present results show that a realistic heat capacity that varies with temperature has significant effects on the detonation pressure, temperature and velocity. Except the velocity, these parameters are overestimated when using constant heat capacities derived from the pre-shock mixtures, and underestimated when using constant heat capacities derived from the combustion product.

The role of particle diameters is also investigated in the simulations. A large particle diameter slows the reaction such that the length scale increases. In the constant heat capacity case, the characteristic combustion length is proportional to the particle diameters with a power law dependence of 1.77 , while the power law dependence is 1.49 for the realistic heat capacity case. This indicates that the heat capacity effects are a function of particle diameters. Moreover, an "abnormal" strong detonation wave may appear in the case of large particle diameters when realistic heat capacities are used. This is consistent with the current combustion model. It is expected that the heat release should vary with temperature in the way similar to that observed for the heat capacity.

\section{Acknowledgment}

The research is supported by The National Natural Science Foundation of China NSFC No. 90916028.

\section{References}

[1] R.K. Eckhoff, J. Hazard. Mater. 35 (1993) 103-117, http://dx.doi.org/10.1016/ 0304-3894(93)85026-B.
[2] R.W. Bartlett, J.N. Ong Jr, W.M. Fassell Jr., C.A. Papp, Combust. Flame 7 (1963) 227-234, http://dx.doi.org/10.1016/0010-2180(63)90187-1.

[3] J.C. Melcher, H. Krier, R.L. Burton, J. Propul. Power 18 (2002) 631-640, http:// dx.doi.org/10.2514/2.5977.

[4] I. Glassman, R.A. Yetter, Combustion, fourth ed., Elsevier, Oxford, UK, 2008.

[5] E.L. Dreizin, Prog. Energy Combust. Sci. 36 (2000) 57-78, http://dx.doi.org/ 10.1016/S0360-1285(99)00010-6.

[6] F. Zhang, AIP Conf. Proc. 1426 (2012) 27-34, http://dx.doi.org/10.1063/ 1.3686215.

[7] A.J. Tulis, J.R. Selman, Proc. Combust. Inst. 19 (1982) 655-663.

[8] A.A. Borisov, B.A. Khasainov, E.L. Saneev, I.B. Formin, S.V. Khomik, B. Veyssiere, in: A.A. Borisov (Ed.), Dynamic Structure of Detonation in Gaseous and Dispersed Media, Kluwer Academic, Dordrecht, The Netherlands, 1991.

[9] F. Zhang, H. Grönig, A. van de Ven, Shock Waves 11 (2001) 53-71, http:// dx.doi.org/10.1007/PL00004060.

[10] Z. Chen, B. Fan, J. Loss Prevent Proc. 18 (2005) 13-19, http://dx.doi.org/ 10.1016/j.jlp. 2004.10.001.

[11] Q. Liu, X. Li, C. Bai, Combust. Flame 156 (2009) 914-921, http://dx.doi.org/ 10.1016/j.combustflame.2008.10.025.

[12] M.R. Baer, J.W. Nunziato, Int. J. Multiphase Flow 12 (1986) 861-889, http:// dx.doi.org/10.1016/0301-9322(86)90033-9.

[13] M.V. Papalexandris, J. Fluid Mech. 517 (2004) 103-112, http://dx.doi.org/ 10.1017/S0022112004000874.

[14] C. Varsakelis, M.V. Papalexandris, J. Fluid Mech. 669 (2011) 472-497, http:// dx.doi.org/10.1017/S0022112010005173.

[15] A.V. Fedorov, T.A. Khmel, V.M. Fomin, Shock Waves 9 (1999) 313-318, http:// dx.doi.org/10.1007/s001930050191.

[16] A.V. Fedorov, V.M. Fomin, T.A. Khmel, Combust. Explos. Shock Waves 45 (2009) 495-505, http://dx.doi.org/10.1007/s10573-009-0060-2.

[17] M.V. Papalexandris, J. Fluid Mech. 507 (2004) 95-142, http://dx.doi.org/ $10.1017 /$ S0022112004008894.

[18] M.V. Papalexandris, Combust. Flame 141 (2005) 216-228, http://dx.doi.org/ 10.1016/j.combustflame.2004.12.017.

[19] K. Benkiewicz, A.K. Hayashi, AIAA J. 44 (2006) 608-619, http://dx.doi.org/ 10.2514/1.20412.

[20] K. Benkiewicz, A.K. Hayashi, Shock Waves 13 (2003) 385-402, http:// dx.doi.org/10.1007/s00193-002-0169-7.

[21] A.V. Fedorov, T.A. Khmel, Y.V. Kratova, Shock Waves 18 (2008) 281-290, http://dx.doi.org/10.1007/s00193-008-0162-x.

[22] A.V. Fedorov, T.A. Khmel, Y.V. Kratova, Shock Waves 20 (2010) 509-519, http://dx.doi.org/10.1007/s00193-010-0290-y.

[23] B. Veyssiere, B.A. Khasainov, A. Briand, Shock Waves 18 (2008) 307-315, http://dx.doi.org/10.1007/s00193-008-0136-z.

[24] K.P. Brooks, M.W. Beckstead, J. Propul. Power 11 (1995) 769-780, http:// dx.doi.org/10.2514/3.23902.

[25] P. Lynch, H. Krier, N. Glumac, Proc. Combust. Inst. 32 (2009) 1887-1893, http://dx.doi.org/10.1016/j.proci.2008.06.205.

[26] T. Bazyn, H. Krier, N. Glumac, Combust. Flame 145 (2006) 703-713, http:// dx.doi.org/10.1016/j.combustflame.2005.12.017.

[27] P. Lynch, F. Giovanni, H. Krier, N. Glumac, Combust. Sci. Technol. 182 (2010) 842-857, http://dx.doi.org/10.1080/00102200600637261.

[28] V. Tanguay, S. Goroshin, A.J. Higgins, F. Zhang, Combust. Sci. Technol. 181 (2009) 670-693, http://dx.doi.org/10.1080/00102200802643430.

[29] R.A. Yetter, G.A. Risha, S.F. Son, Proc. Combust. Inst. 32 (2009) 1819-1838, http://dx.doi.org/10.1016/j.proci.2008.08.013.

[30] F. Zhang, K. Gerrard, R.C. Ripley, J. Propul. Power 25 (2009) 845-858, http:// dx.doi.org/10.2514/1.41707.

[31] A. Briand, B. Veyssiere, B.A. Khasainov, Shock Waves 20 (2010) 521-529, http://dx.doi.org/10.1007/s00193-010-0288-5.

[32] B. Veyssiere, A. Khasainov, Combust. Flame 85 (1991) 241-253.

[33] E.S. Oran, J.W. Weber, E.I. Stefaniw, M.H. Lefebvre, J.D. Anderson, Combust. Flame 113 (1998) 147-163.

[34] N. Tsuboi, K. Eto, A.K. Hayashi, Combust. Flame 149 (2007) 144-161.

[35] NIST Chemistry WebBook, <http://webbook.nist.gov/chemistry/>.

[36] B.J. McBride, M.J. Zehe, S. Gordon, NASA Glenn Coefficients for Calculating Thermodynamic Properties of Individual Species, NASA TP-2002-211556, 2002.

[37] Z.L. Jiang, Acta Mech. Sin. 20 (2004) 1-15.

[38] F. Zhang, S.B. Murray, K.B. Gerrard, Shock Waves 15 (2006) 313-324

[39] F. Zhang, J. Propul. Power 22 (2006) 1289-1309.

[40] W. Fickett, W.C. Davis, Detonation, University of California Press, Berkeley, US, 1979.

[41] B. Veyssiere, B.A. Khasainov, Shock Waves 4 (1995) 171-186, http://dx.doi.org/ 10.1007/BF01414983.

[42] R.O. Carvel, G.O. Thomas, C.J. Brown, Shock Waves 13 (2003) 83-89, http:// dx.doi.org/10.1007/s00193-003-0190-5. 